\title{
Parent-Infant Attachment Insecurity and Emotional Eating in Adolescence: Mediation through Emotion Suppression and Alexithymia
}

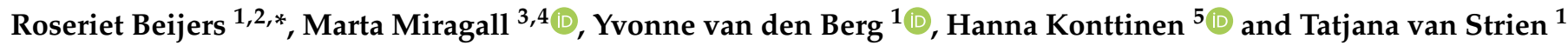 \\ 1 Behavioural Science Institute, Radboud University, 6525 XZ Nijmegen, The Netherlands; \\ y.vandenberg@psych.ru.nl (Y.v.d.B.); t.vanstrien@psych.ru.nl (T.v.S.) \\ 2 Donders Institute, Radboudumc, 6525 GA Nijmegen, The Netherlands \\ 3 Department of Personality, Evaluation, and Psychological Treatments, University of Valencia, \\ 46010 València, Spain; marta.miragall@uv.es \\ 4 CIBER Fisiopatología Obesidad y Nutrición (CIBEROBN), Instituto Carlos III, 28029 Madrid, Spain \\ 5 Faculty of Social Sciences, University of Helsinki, 00100 Helsinki, Finland; hanna.konttinen@helsinki.fi \\ * Correspondence: r.beijers@psych.ru.nl
}

check for updates

Citation: Beijers, R.; Miragall, M.; van den Berg, Y.; Konttinen, H.; van Strien, T. Parent-Infant Attachment Insecurity and Emotional Eating in Adolescence: Mediation through Emotion Suppression and Alexithymia. Nutrients 2021, 13, 1662. https://doi.org/10.3390/nu13051662

Academic Editor:

Fernando Fernandez-Aranda

Received: 17 March 2021

Accepted: 29 April 2021

Published: 14 May 2021

Publisher's Note: MDPI stays neutral with regard to jurisdictional claims in published maps and institutional affiliations.

Copyright: (c) 2021 by the authors. Licensee MDPI, Basel, Switzerland. This article is an open access article distributed under the terms and conditions of the Creative Commons Attribution (CC BY) license (https:// creativecommons.org/licenses/by/ $4.0 /)$.

\begin{abstract}
Emotional eating (EE), the propensity to eat in response to emotions, is thought to have its origins in the early parent-infant relationship. This study tested the hypothesis that infant attachment insecurity results in $\mathrm{EE}$ in adolescence through the increased use of the emotion regulation strategy suppression of emotions and subsequent alexithymia. At the age of 15 months, parentinfant attachment security $(n=129)$ was observed with two abbreviated attachment measures: the shortened strange situation procedure (SSSP), and the shortened attachment Q-set (S-AQS). At the age of 12 years, children completed self-report questionnaires to assess the suppression of emotions, alexithymia, and EE. At the age of 16 years, EE was measured again. The mediation models indicated that lower parent-infant attachment security predicted increased use of suppression of emotions, which was related to increased alexithymia, and in turn more EE at the age of 12 years. These results were similar and significant for both attachment measures, and also (marginal) significant with EE at the age of 16 years as an outcome. Lastly, when parental caregiving quality was included, the models with the SSSP as predictor remained significant, but the models with the S-AQS became insignificant. These results indicated that to a certain extent, infant attachment security could predict adolescent EE above and beyond parental caregiving quality.
\end{abstract}

Keywords: parent-child attachment; strange situation procedure; attachment Q-set; emotional eating; emotion suppression; alexithymia

\section{Introduction}

Emotional Eating [EE], the propensity to eat in response to emotions, is considered an atypical response to stress. As the physiological stress response mimics the internal sensations associated with feeding induced satiety, the typical response to stress is not eating [1]. When stressed, emotional eaters tend to eat energy-dense food (e.g., [2-5]), which in turn can result in weight gain and obesity [6-8]. It is therefore important to increase our understanding of the antecedents of EE.

\subsection{Parent-Infant Attachment and EE}

EE is thought to have its origins in the early caregiving environment $[9,10]$, including the parent-infant attachment relationship. Attachment is the emotional bond that forms between the infant and the primary caregiver(s), usually the parent(s) [11]. In times of stress, securely attached infants go to the parent for protection and comfort, after which they return to exploring the world around them. Insecurely attached infants are not able to use the parent as a "safe haven" or "secure base", and experience difficulties 
coping with stress. In this light, longitudinal research has shown that infant attachment insecurity forecasts a range of later negative child developmental outcomes, including socio-emotional behavior [12]. Though EE is considered an atypical response to stress, and as such might represent difficulties coping with stress, it is yet unclear whether infant's attachment insecurity also forecasts later EE.

Though associations between attachment insecurity and unhealthy eating behaviors have been consistently found [13-15], the studies to date mostly focused on adult attachment representations, using self-report, and employed cross-sectional designs. Both adult attachment representations and EE stem from complex developmental processes with their onset in infancy. Longitudinal studies starting in early life are thus clearly needed to start unravelling cause-effect associations between attachment and EE $[13,16]$. Moreover, previous studies on attachment insecurity and unhealthy eating behaviors mostly focused on eating pathology in clinical samples. For example, higher rates of insecure attachment have been found in patients with eating disorders, including anorexia nervosa and bulimia nervosa, compared to rates in community samples [17-19]. By focusing on pathological eaters, it remains unclear whether attachment insecurity is linked to eating behaviors in the general population [13]. The few studies that did investigate attachment security and EE, indicated that attachment insecurity increases the risk for EE in bariatric surgery candidates and patients [20-22], and that EE mediated the association between attachment anxiety and body mass index (BMI) [23], but not between disorganized and BMI [15]. As such, the first aim was to longitudinally investigate if attachment security observed in infancy predicts EE in adolescence.

\subsection{Measures of Parent-Infant Attachment}

We measured parent-infant attachment security with two abbreviated measures of well-known attachment measures: The strange situation procedure (SSP) [24], and the attachment Q-set (AQS) $[25,26]$. The SSP and the AQS are different in many ways. The SSP is a structured procedure at the laboratory to assess whether infants can use the parent as a safe haven to return to in times of stress [24]. The abbreviated version of the SSP uses one separation, instead of two, to observe the child's reunion behavior towards the parent. The AQS is an observation at home to assess whether infants can use the parent as a secure base. The AQS consists of 90 cards describing attachment-related behaviors. The observer sorts the cards and a security score is obtained by correlating the child's individual sort with the sort of a prototypically secure child $[25,26]$. The abbreviated version of the AQS implies that the observation was based on $2 \mathrm{~h}$, instead of $3 \mathrm{X} 3 \mathrm{~h}$, of home observations. Both abbreviated measures of the SSP and the AQS have been shown valid [27-29].

The SSP and the AQS measures reveal how the child's attachment system functions in different situations. The SSP focuses on the dynamics of the attachment system in new, stressful situations, while the AQS focuses on the dynamics in the natural home setting [30]. In this light, this study will exploratorily examine whether both attachment measures can predict adolescent EE.

\subsection{Mediators between Parent-Infant Attachment and EE}

Accumulating evidence suggests that dysfunctional emotion regulatory capacities serve as a potential underlying mechanism relating attachment insecurity to EE [22,31-33]. Securely attached infants are better able to regulate and modulate their emotions through the process of co-regulation [34-39]. Co-regulation refers to the process of responsive parents protecting the infant from high levels of stress, and simultaneously promoting the infant's own emergent capacities to regulate stress. Insecurely attached children are thus suggested to have developed dysfunctional emotion regulatory capacities [34-36], which in turn might predict EE.

Increased use of emotion suppression is suggested to be such a dysfunctional emotion regulation strategy [40]. Suppression of emotions involves the inhibition of expression of ongoing emotions and related behaviors. While lower parenting quality has been 
associated with an increased use of suppression of emotions [40,41], we are not aware of studies linking attachment insecurity to this emotion regulation strategy. However, one study in mothers and their 4,5-year-old children found attachment insecurity to be associated with higher child avoidance to discuss emotions of sadness and anger [42]. This study provides preliminary evidence that attachment insecurity is associated with suppression of emotions. In turn, suppression of emotions has been associated with alexithymia $[40,43,44]$. Alexithymia is defined as the inability to identify and describe emotions experienced by one's self or others. As studies have related alexithymia to EE $[40,45,46]$, the second aim was to investigate whether the emotion regulation strategy of emotion suppression, and subsequent alexithymia, mediates the infant attachment insecurity-adolescent EE association.

\subsection{Aims of the Present Study}

We aimed to test the hypothesis that parent-infant attachment insecurity predicts increased use of suppression of emotions, which relates to alexithymia, and subsequent EE in adolescence. In an earlier study on the same cohort, lower parental caregiving quality in infancy forecasted more EE in adolescence [40]. On this basis, and the notion that sensitivity is one, but not only antecedent of attachment security [47], we also investigated the hypothesis that infant attachment security can predict adolescent EE, above and beyond parental caregiving quality. By identifying possible predictors and developmental pathways by which the vulnerability to develop EE across development increases, this study contributes to assessment, prevention and treatment of EE.

\section{Method}

\subsection{Participants}

The data came from the ongoing Nijmegen longitudinal study [NLS]. Families with a 15-month-old infant were recruited via local health-care centers in Nijmegen (The Netherlands). Inclusion criteria were having sufficient fluency in Dutch, and having a child without serious health conditions. Of the 639 families approached, 174 were interested in participation and 129 families were randomly selected (the maximum number given the time and resources available for the study). For more information on the NLS, see [48,49].

The 129 children ( 67 boys, 62 girls) had a mean age of 15.1 months old ( $S D=0.3$ months). The majority of the children were from two-parent families (95\%) and from families in which the mother was the primary caregiver $(98 \%)$. The primary caregivers were between 22 and 47 years old $(M=32.9$ years, $S D=4.4)$ and representative of the Dutch population in socioeconomic background. For the present study, 104 children had complete data until the age of 12 years. When the EE measure at the age of 16 years was included, 91 children had complete data. See also Figure 1 for the NLS flowchart. The study procedures were approved by the Institutional Review Board of the Radboud University (ECG-20213-1811-157).

\subsection{Procedure}

At the age of 15 months, the two abbreviated measures to measure infant attachment security were performed during a visit to the laboratory and a home visit. Additionally, a 12 to $15 \mathrm{~min}$ semi-structured parent-infant interaction was recorded during the home visit. During the 28-month assessment, another parent-child interaction was recorded during a home visit. At the age of 12 years, data were collected during a home visit. Children completed questionnaires to assess their use of suppression of emotions, alexithymia, and EE. At the age of age 16 years, data were collected during a school visit. Children completed a questionnaire on $\mathrm{EE}$. 


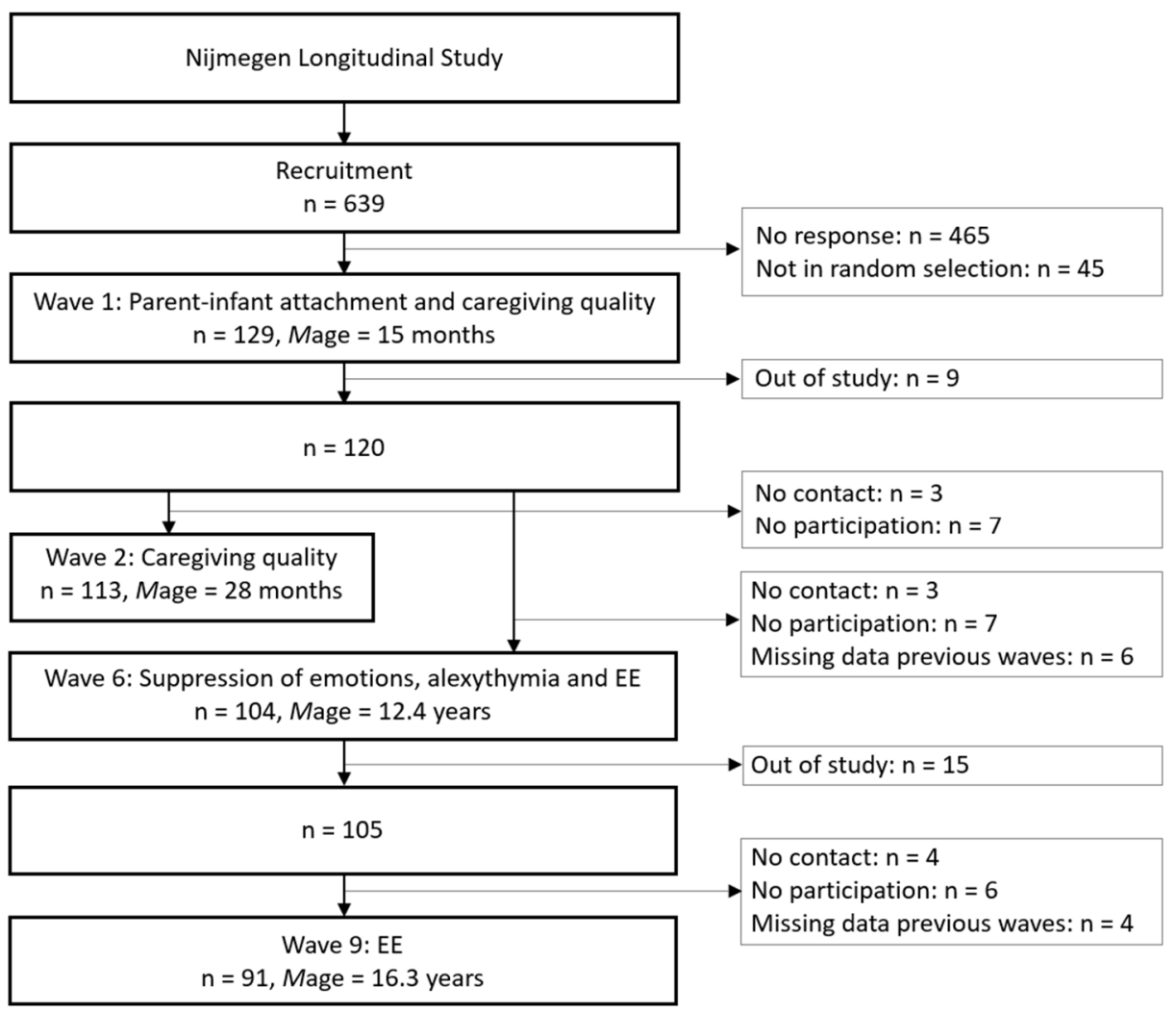

Figure 1. Nijmegen Longitudinal Study (NLS) flowchart.

\subsection{Measures}

\subsubsection{The Shortened Strange Situation Procedure (SSSP)}

The Shortened Strange Situation Procedure (SSSP) consists of three episodes: parent and infant in the room (3 $\mathrm{min})$, infant alone (4 $\mathrm{min})$, and parent-infant reunion (3 $\mathrm{min})$ [24]. To increase the stressfulness, the duration of the separation was increased from $3 \mathrm{~min}$ to $4 \mathrm{~min}$. Two trained coders rated the videotaped SSSP's and classified the infants as secure (B), avoidant (A), resistant (C), or disorganized (D). With $95 \%$ agreement on the main classifications, intercoder reliability was adequate $(n=20$ cases). More information regarding the validity of the SSSP and its scoring, see [30,49]. For this study, a dummy variable was created representing secure attachment $(B)$ versus insecure attachment (A, C, and D). In our sample of 104 participants at the age of 12 years, 67 infants $(64 \%)$ had been classified as securely attached and 37 infants (36\%) as insecurely attached (i.e., 16 infants with label A, 8 infants with label C, and 13 infants with label D).

\subsubsection{The Shortened Version of the Attachment Q-Set (S-AQS)}

The Dutch translation of the AQS [25] was applied on two hours of home observations, which is considerably less than the $3 \times 3 \mathrm{~h}$ prescribed by Waters and Deane [26]. While larger effect sizes are indicated for the association between SSP security and AQS security when AQS observations lasted >three hours, compared to AQS observations of $\leq$ three hours, the AQS observation duration did not affect the association between AQS security and later child outcomes [29]. The observer was trained until a reliability of 0.75 was reached. Subsequent reliability checks for five independent sorts for the same children exceeded the standard of 0.75 . More information regarding the validity of the S-AQS and its scoring, see $[30,49]$.

\subsubsection{Emotion Regulation Strategy of Suppression of Emotions (12 Years)}

Children completed the 10-item Emotion Regulation Questionnaire [50]. Four items measure suppression of emotions. The items were rated along a seven-point scale ranging 
from strongly disagree to strongly agree. Higher scores reflect more use of suppression of emotions.

\subsubsection{Alexithymia (12 Years)}

Alexithymia difficulty identifying feelings was measured with the corresponding subscale of the Toronto Alexithymia Scale-20 (TAS-20) [51-53]. The subscale has seven items that were rated along a three-point scale. Higher scores reflect more alexithymia.

\subsubsection{Emotional Eating (EE; 12 Years and 16 Years)}

$\mathrm{EE}$ at the age of 12 years was assessed with seven items of an age-adapted 20-item version of the Dutch Eating Behavior Questionnaire (DEBQ), which is suitable for 7- to 12-year-old children (DEBQ-C [54]). The items were rated along a 5-point scale ranging from never to very often. Higher scores reflect more EE.

$\mathrm{EE}$ at the age of 16 years was assessed with six items of the brief version of the adult version of the DEBQ [55]. The items were rated on a five-point scale from never to very often. Higher scores reflect more EE.

\subsubsection{Parental Educational Level}

Maternal and paternal educational level were rated on a 7-point scale. Because of high intercorrelations $(r=0.69)$, the mean of paternal and maternal educational level was calculated and included as confounder in the main analyses.

\subsubsection{Parental Caregiving Quality ( 15 and 28 Months of Age)}

To test whether infant attachment security can predict adolescent EE, above and beyond parental caregiving quality [40], parental caregiving quality was observed at child age 15 and 28 months. The two recorded parent-child interactions were rated for: (1) supportive presence (e.g., the extent to which caregivers provide emotional support); (2) respect for the autonomy of the child (e.g., the extent to which caregivers adjust to their child and do not interfere with ongoing activity); and (3) hostility (i.e., the extent to which caregivers express anger or rejection of the child). Independent coding of 25 cases yielded interrater reliabilities above 0.83 for all scales. Parental caregiving quality was computed with the SOM ratio of positive parenting to the sum of positive plus negative parenting. For further details, see [40].

\subsection{Data Analyses}

Descriptive statistics and Pearson's correlation between the study variables were conducted in order to analyze the mean, standard deviation, and relationships between the study variables. These preliminary analyses were conducted both within the sample of completers of the DEBQ-C at the age of 12 years, and within the sample of completers of the DEBQ at the age of 16 years.

For the main analyses, serial multiple mediator analyses were performed with the macro PROCESS version 2.16 for SPSS [56]. Model 6 was chosen to test whether the association between attachment security and EE was mediated by suppression of emotions and alexithymia. Four mediation analyses were conducted as the models were separately tested for the two variables of attachment security (SSSP and S-AQS), and separately tested for completers of the eating behavior questionnaire at the age of 12 and 16 years. Child sex and parental educational level were entered as covariates. The mediational effect was significant, respectively borderline significant, when the $95 \%$, respectively, $90 \%$ confidence intervals (CIs) of the indirect effect did not include the zero-value. Regression coefficients are reported in unstandardized form as b-values.

Subsequently, the confidence intervals of the three specific indirect effects were inspected: (1) the single mediation effect through emotion suppression, (2) the single mediation effect through alexithymia difficulty identifying emotions, and (3) the serial mediation effect through emotion suppression and alexithymia. Bias-corrected bootstrap 95\% CI 
based on 5000 samples were used. The bootstrapping approach has been recommended by several authors to test mediation. Compared to more traditional methods, the bootstrapping approach has the highest statistical power and the best Type I error control yielding results that are more accurate and less affected by sample size [57-59].

As we found in an earlier study on the same cohort that lower parental caregiving quality in infancy forecasted more EE in adolescence [40], all models will be re-run including parental caregiving quality to investigate whether infant attachment security can predict adolescent EE, above and beyond parental caregiving quality.

\section{Results}

\subsection{Preliminary Analyses}

Descriptive statistics and Pearson's correlations between the study variables are shown in Table 1. The Pearson's correlations without brackets present the correlations for the group of completers of the DEBQ-C at the age of 12 years $(n=104)$, and the Pearson's correlations between brackets present the correlations for the group of completers of the DEBQ at the age of 16 years $(n=91)$. No outliers were detected.

Table 1. Correlations and descriptive statistics of the study variables at 12 (shown without brackets) and 16 years of age (shown between brackets).

\begin{tabular}{|c|c|c|c|c|c|c|c|}
\hline & $\begin{array}{l}\text { Attachment } \\
\text { Security } \\
\text { (SSSP) }\end{array}$ & $\begin{array}{l}\text { Attachment } \\
\text { Security } \\
\text { (S-AQS) }\end{array}$ & $\begin{array}{l}\text { Suppression } \\
\text { of Emotions }\end{array}$ & Alexithymia & $\begin{array}{l}\text { Emotional } \\
\text { Eating }\end{array}$ & $\begin{array}{l}\text { Child } \\
\text { Sex }\end{array}$ & $\begin{array}{c}\text { Parental } \\
\text { Educational } \\
\text { Level }\end{array}$ \\
\hline $\begin{array}{c}\text { Attachment } \\
\text { security (SSSP) }\end{array}$ & - & & & & & & \\
\hline $\begin{array}{l}\text { Attachment } \\
\text { security } \\
\text { (S-AQS) }\end{array}$ & $0.27^{* *}(0.20)$ & - & & & & & \\
\hline $\begin{array}{l}\text { Suppression of } \\
\text { emotions }\end{array}$ & $\begin{array}{l}-0.30^{* *} \\
\left(-0.25^{*}\right)\end{array}$ & $\begin{array}{l}-0.26 \text { ** } \\
(-0.20)\end{array}$ & - & & & & \\
\hline Alexithymia & $0.04(0.01)$ & $\begin{array}{l}-0.14 \\
(-0.17)\end{array}$ & $0.33^{* *}\left(0.37^{* * *}\right)$ & - & & & \\
\hline $\begin{array}{l}\text { Emotional } \\
\text { eating }\end{array}$ & $0.10(0.14)$ & $0.07\left(0.28^{* *}\right)$ & $0.12(-0.14)$ & $0.44^{* * *}(0.21 *)$ & - & & \\
\hline Child sex & $0.15(0.12)$ & $0.15(0.16)$ & $-0.08(-0.08)$ & $0.18(0.18)$ & $0.15\left(0.41^{* * *}\right)$ & - & \\
\hline $\begin{array}{c}\text { Parental } \\
\text { educational } \\
\text { level }\end{array}$ & $0.06(-0.00)$ & $0.01(-0.06)$ & $-0.08(0.00)$ & $-0.03(-0.06)$ & $0.14(0.21 *)$ & $\begin{array}{c}-0.12 \\
(-0.14)\end{array}$ & - \\
\hline $\mathrm{M}$ & $0.6(0.7)$ & $0.3(0.3)$ & $3.3(3.2)$ & $9.4(9.4)$ & $1.7(2.2)$ & $1.5(1.5)$ & $5.2(5.2)$ \\
\hline $\begin{array}{l}\text { Standard } \\
\text { Deviation }\end{array}$ & $0.5(0.5)$ & $0.3(0.2)$ & $1.2(1.2)$ & $2.3(2.3)$ & $0.7(1.0)$ & $0.5(0.5)$ & $1.6(1.6)$ \\
\hline
\end{tabular}

Notes. ${ }^{* * *} p<0.001 ;{ }^{* *} p<0.01 ; * p<0.05$. S-AQS = shortened attachment Q sort; SSSP = shortened strange situation procedure.

Correlations

Within the group completers of the DEBQ-C at the age of 12 years, the two attachment security measures (SSSP and S-AQS) were positively correlated, and the strength of the association was moderate. None of the two attachment security measures were significantly associated with EE. Both measures of attachment security were associated with suppression of emotions, indicating that higher attachment security was associated with lower suppression of emotions. More suppression of emotions was moderately associated with more alexithymia difficulty identifying feelings, and more alexithymia difficulty identifying feelings was moderately associated with higher EE.

Within the group completers of the DEBQ at the age of 16 years, attachment security, as assessed with the SSSP, was not associated with EE at the age of 16 years. In contrast, and remarkably, attachment security as measured with the S-AQS was significantly and positively associated with EE, indicating that higher attachment security was associated with higher degrees of EE. A significant negative relationship was found between attachment security as measured by the SSSP and suppression of emotions, whilst the negative relationship between attachment security as measured by the S-AQS and suppression of emotions just failed to reach significance. More suppression of emotions was associated 
with more difficulty identifying feelings, and more difficulty identifying feelings was associated with higher degrees of EE. Finally, female adolescents and adolescents with more educated parents reported higher degrees of $\mathrm{EE}$ at the age of 16 years.

\subsection{Serial Multiple Mediation Analyses}

\subsubsection{Emotional Eating at 12 Years}

Though there was no significant association between infant attachment security, as measured with both the SSSP and S-AQS, and adolescent EE, there is agreement that mediation can exist even in the absence of an overall significant association [60,61]. Therefore, we proceeded to test the mediation models. Unstandardized regression coefficients and standard errors of the full model, and confidence intervals of the direct effects, are shown in Figure 2.
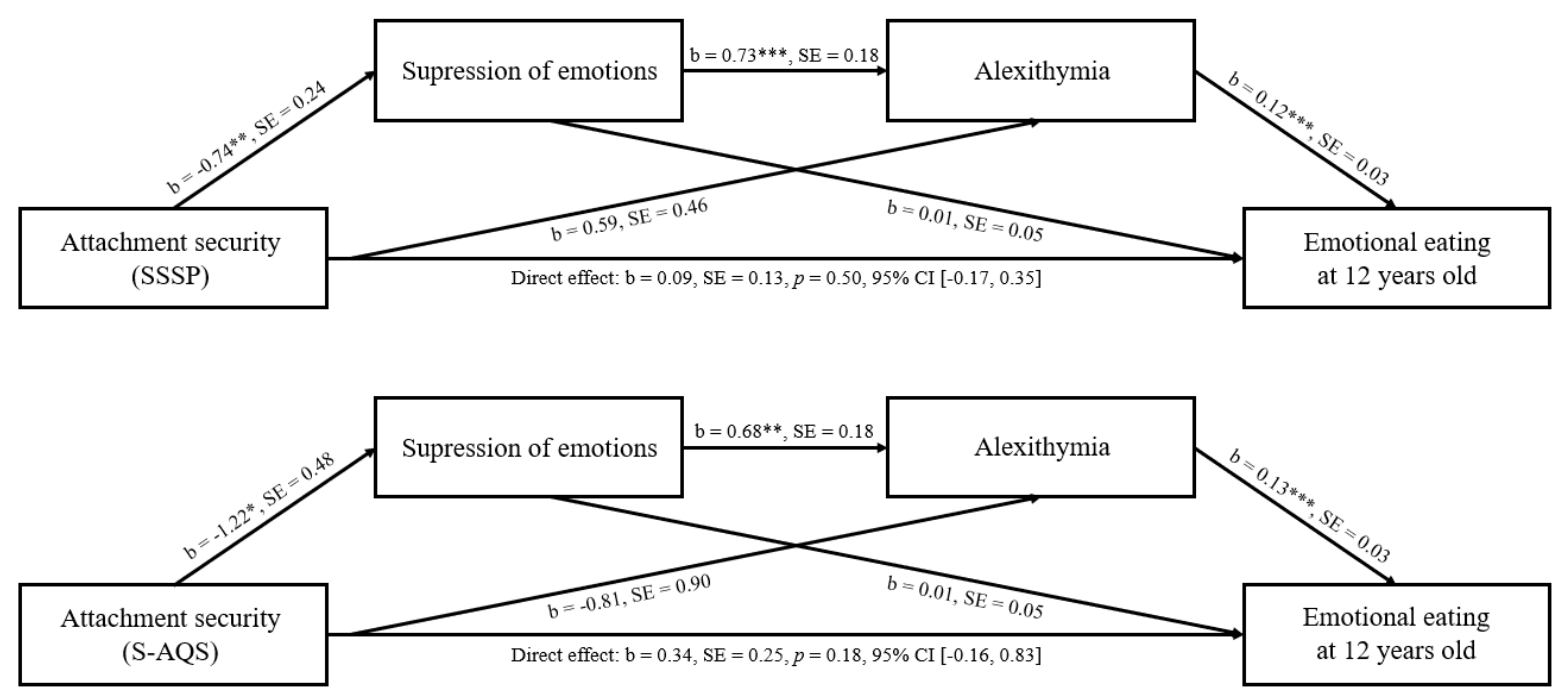

Figure 2. Suppression of emotions and alexithymia as mediators between attachment security and emotional eating at the age of 12 years old. Notes. ${ }^{*} p<0.05 ;{ }^{* *} p<0.01 ;{ }^{* * *} p<0.001 . \mathrm{b}=$ unstandardized regression coefficients; $\mathrm{SE}=$ standard errors; SSSP = shortened strange situation procedure, S-AQS = shortened attachment Q-set.

Attachment Security as Measured by the SSSP

The total indirect effect (the difference between total and direct effect $\left.\left(\mathrm{c}-\mathrm{c}^{\prime}\right)\right)$ was not significant $(b=0.00, \mathrm{SE}=0.08,95 \% \mathrm{CI}(-0.16,0.14))$. The indirect effects associated with model 1 and model 2 were not significant $(\mathrm{b}=-0.01$, SE $=0.04,95 \% \mathrm{CI}(-0.11,0.07)$, and $\mathrm{b}=0.07, \mathrm{SE}=0.06,95 \% \mathrm{CI}(-0.04,0.21)$, respectively). Only the indirect effect of model 3 (the serial mediation effect through emotion suppression and alexithymia) was significant $(\mathrm{b}=-0.07, \mathrm{SE}=0.03,95 \% \mathrm{CI}(-0.15,-0.02))$. The multiple regression model including all the variables was significant $(F(5,98)=5.91, p<0.001)$, and explained $23.2 \%$ of the variance in EE.

\section{Attachment Security as Measured by the S-AQS}

Again, the total indirect effect was not significant $(b=-0.21, \mathrm{SE}=0.15,95 \% \mathrm{CI}(-0.56$, $0.04)$ ). The indirect effects associated with model 1 and model 2 were also not significant $(\mathrm{b}=-0.01, \mathrm{SE}=0.06,95 \% \mathrm{CI}(-0.17,0.10)$, and $\mathrm{b}=-0.10, \mathrm{SE}=0.12,95 \% \mathrm{CI}(-0.38$, 0.11 ), respectively). Only the indirect effect of model 3 (the serial mediation effect through suppression of emotions and alexithymia) was significant $(b=-0.10, \mathrm{SE}=0.05,95 \% \mathrm{CI}$ $(-0.23,-0.02))$. The multiple regression model including all the variables was significant $(F(5,98)=6.27, p<0.001)$, and explained $24.25 \%$ of the variance in EE. 


\section{Parental Caregiving}

To investigate whether infant attachment security can predict adolescent $\mathrm{EE}$, above and beyond parental caregiving quality, models were re-run including parental caregiving quality. In the model with SSSP attachment security, the indirect effect of model 3 remained significant $(\mathrm{b}=-0.05, \mathrm{SE}=0.02,95 \% \mathrm{CI}(-0.12,-0.01))$, but when attachment security was measured with the S-AQS, the indirect effect of model 3 became insignificant $(b=-0.04$, $\mathrm{SE}=0.04,95 \% \mathrm{CI}(-0.13,0.02))$.

\subsubsection{Emotional Eating at 16 Years}

The analyses were re-conducted with EE at the age of 16 years. See Figure 3 for the unstandardized regression coefficients and standard errors for the full model, in addition to the confidence intervals of the direct effects.
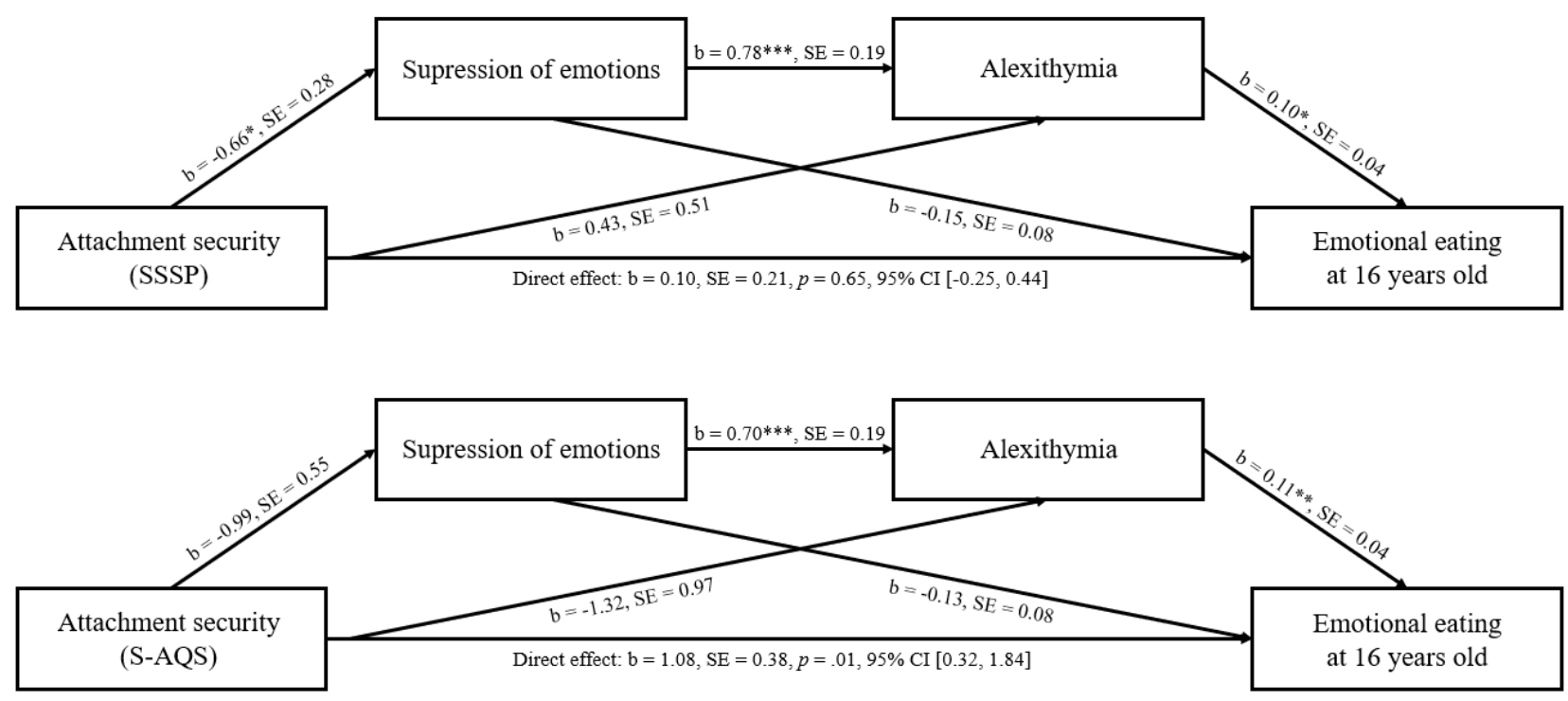

Figure 3. Suppression of emotions and alexithymia as mediators between attachment security and emotional eating at the age of 16 years old. Notes. ${ }^{*} p<0.05 ;{ }^{* *} p<0.01 ;{ }^{* *} p<0.001 . \mathrm{b}=$ unstandardized regression coefficients; $\mathrm{SE}=$ standard errors; SSSP = shortened strange situation procedure, S-AQS = shortened attachment Q-set.

Attachment Security as Measured by the SSSP

The total indirect effect was not significant $(b=0.09, \mathrm{SE}=0.08,95 \% \mathrm{CI}(-0.04,0.30))$, and the same held true for the indirect effects of model 1 and model $2(b=0.10, \mathrm{SE}=0.07$, $95 \% \mathrm{CI}(0.01,0.31)$ and $\mathrm{b}=0.04, \mathrm{SE}=0.07,95 \% \mathrm{CI}(-0.03,0.29)$, respectively). The indirect effect of the serial mediation model 3 was not significant at $95 \% \mathrm{CI}(\mathrm{b}=-0.05, \mathrm{SE}=0.04$, $95 \% \mathrm{CI}(-0.20,-0.02))$, but it was significant at $90 \% \mathrm{CI}(\mathrm{b}=-0.05, \mathrm{SE}=0.04,90 \% \mathrm{CI}$ $(-0.17,-0.01))$. The regression model which included all the variables was significant $(F(5,85)=7.15, p<0.001)$, and explained $29.6 \%$ of the variance in EE.

Attachment Security as Measured by the S-AQS

The total indirect effect was not significant $(b=-0.10, \mathrm{SE}=0.16,95 \% \mathrm{CI}(-0.55,0.13))$. Moreover, the indirect effects associated with model 1 and model 2 were not significant $(\mathrm{b}=0.13, \mathrm{SE}=0.12,95 \% \mathrm{CI}(-0.01,0.51)$, and $\mathrm{b}=-0.15, \mathrm{SE}=0.12,95 \% \mathrm{CI}(-0.54,0.00)$, respectively). The indirect effect of model 3 was significant at $95 \% \mathrm{CI}(\mathrm{b}=-0.08, \mathrm{SE}=0.07$, $95 \%$ CI $(-0.32,-0.0006))$. The multiple regression model including all the variables was significant $(F(5,85)=9.37, p<0.001)$, and explained $35.5 \%$ of the variance in the EE.

Parental Caregiving Quality

To investigate whether infant attachment security can predict adolescent EE, above and beyond parental caregiving quality, models were re-run including parental caregiving 
quality. In the model with SSSP attachment security, the indirect effect of model 3 was significant $(\mathrm{b}=-0.04, \mathrm{SE}=0.04,95 \% \mathrm{CI}(-0.19,-0.004))$, but when attachment security was measured with S-AQS, the indirect effect of model 3 became insignificant $(b=-0.01$, $\mathrm{SE}=0.05,95 \% \mathrm{CI}(-0.17,0.06))$.

\section{Discussion}

The present study tested the hypothesis that attachment insecurity in infancy results in emotional eating (EE) in adolescence through the increased use of the emotion regulation strategy of emotion suppression and subsequent alexithymia. We examined whether this hypothesis would hold for the two abbreviated versions of the attachment measures used in this study: The shortened strange situation procedure (SSSP) [24], and the shortened version of the attachment Q-set (S-AQS) $[25,26]$. In support of our hypotheses, the mediation models indicated that lower parent-infant attachment security in infancy predicted increased suppression of emotions, which in turn was related to more alexithymia, and ultimately more EE at the age of 12 years. These results were similar and significant for both attachment measures. To test the robustness of the chain as a chain in real time, the analyses were reconducted with EE at the age of 16 years. The serial mediation model with EE at the age of 16 years was significant when attachment security was observed with the S-AQS, and marginally significant when attachment security was observed with the SSSP. Lastly, when parental caregiving quality was included, the models with the SSSP as predictor remained significant, but the models with the S-AQS became insignificant. These results indicated that, to a certain extent, infant attachment security can predict adolescent EE above and beyond parental caregiving quality.

Our results suggest that parent-infant attachment insecurity may increase the risk for EE in adolescence through difficulties with emotion regulation and alexithymia. Though associations between attachment insecurity and unhealthy eating behaviors have been consistently found (e.g., $[13,14])$, the studies to date mostly focused on adult attachment representations and employed cross-sectional designs. The present longitudinal and prospective study thus importantly adds to the field, as longitudinal studies help to unravel cause-effect associations between early attachment and later EE [13,16]. Moreover, this study indicated that not only early parental feeding practices [62-65], but also a more general quality of the parent-infant interaction was associated with EE in adolescents.

A closer investigation of the results indicated that the direct association between the S-AQS attachment measure and EE at the age of 16 years was significant and positive. Apparently, higher parent-infant attachment security, as observed with the abbreviated version of the AQS, was related to higher degrees of EE at the age of 16 years. This association was contrary to our expectations. In contrast, the serial mediation model with S-AQS and EE at the age of 16 years was also significant, and these results were in line with our hypothesis (i.e., lower parent-infant attachment security predicting more EE through increased suppression of emotions and alexithymia). Moreover, this mediational model explained more variance in EE than the model without the mediators (36\% versus $29 \%$, respectively). In addition, the results of the mediational model of S-AQS and EE at the age of 16 years were comparable to the findings with the S-AQS and SSSP at the age of 12 years, and the SSSP at the age of 16 years. In sum, while our findings seem to provide evidence for our initial hypothesis, future research is urged to investigate whether our results are robust and replicate.

Both attachment security measured with the SSSP and the S-AQS predicted EE in adolescence through increased suppression of emotions and alexithymia. This is an interesting finding, especially as these two measures of attachment were only moderately correlated (see Table 1). As such, these findings confirm the assumption that both attachment measures have predictive power of later child outcomes, but at the same time provide different windows into the parent-infant attachment relationship. While the SSSP reflects more the infant's expectations of parental responsiveness in times of stress, the S-AQS reflects more the infant's expectations of parental guidance in times of no stress [30]. As such, both 
attachment measures may therefore complement one another in predicting child outcomes, and infant expectations of parental responses in both times of stress and non-stress seem to be relevant for the development of EE.

This reflection on these attachment measures might also serve as an explanation for the results we found after including parental caregiving quality as a variable in the mediation models. In an earlier study on the same cohort, lower parental caregiving quality in infancy forecasted more EE in adolescence [40]. For this reason, the models were reconducted to investigate whether infant attachment security can predict EE above and beyond parental caregiving quality. While the models with the SSSP remained significant, the models with the S-AQS became insignificant. Parental caregiving quality and the S-AQS were both observed during non-stressful home observations, in contrast to the SSSP, which was observed during a stressful situation in the lab. So, compared to the SSSP, it could be hypothesized that the S-AQS and parental caregiving quality tap more into a similar part of the parent-infant interaction. However, strikingly, post-hoc correlations reveal that the association between the S-AQS and parental caregiving quality was less strong $(r=0.274$, $p=0.006)$, compared to the association between parental caregiving quality and the SSSP $(r=0.421, p<0.001)$. As such, these correlations do not seem to support our hypothesis. For future research, with a larger sample size compared to ours, it would be interesting to investigate to what extent attachment security and parental caregiving quality function as independent predictors of $\mathrm{EE}$, and to what extent attachment security mediates the association between parental caregiving quality and EE. This knowledge would help to unravel the parts of the early parent-infant interaction relevant for the development of $\mathrm{EE}$ and inform programs for preventing EE in adolescence.

This study has many strengths. A first strength is the longitudinal, prospective nature of the study, following parents and their children over a time span of 15 years. Another strength is the multi-method approach used, including parent-infant attachment observations and child self-report to identify emotion suppression, alexithymia, and EE. A further strength is that parent-infant attachment security was observed with not one, but two measures: the SSSP and the S-AQS. The fact that the results were found to be similar with two different attachment measures gives confidence in the robustness of the results. We do have to note that it remains possible that the abbreviated versions of these attachment measures have negatively affected its validity. As a consequence, we can only wonder whether the predictive effects would have been larger when the unabbreviated versions would have been used.

We also have some other limitations to note. Suppression of emotions and alexithymia were measured at the same point in time, i.e., at the age of 12 years. As such, a reverse chain cannot be ruled out, but seems less likely given the literature to date (e.g., [43,44]. Nevertheless, for future studies, we recommend to measure suppression of emotions and alexithymia at different time points, so that more light can be shed on the direction of the chain. Another limitation is the relatively low sample size. Note that the bootstrapping approach was adopted to test the mediation models, as this approach yield results that are less influenced by sample size [58,59]. Nevertheless, the low sample size hampered power and precluded the possibility to investigate the possible moderating effect of child sex. Considering the higher degrees of EE in the female adolescents at the age of 16 years, it would be of interest to investigate possible sex differences in the serial mediation between attachment and EE. The low sample size also prevented us to investigate the different attachment classifications. As a meta-analysis in adults indicated that attachment anxiety was more strongly associated with unhealthy eating behaviors compared to attachment avoidance [13], it is possible that the four infant attachment classifications differently predict $\mathrm{EE}$ in adolescence. In addition, as the different dimensions of attachment security were shown to be related to distinct strategies of emotion regulation in adults [66,67], future studies should also investigate the different attachment classifications in relation to other child emotion regulation strategies, including cognitive reappraisal. 


\section{Conclusions}

To the best of our knowledge, this study provides the first evidence that infant attachment security predicts adolescent EE longitudinally through mediation of emotion suppression and alexithymia. In line with studies showing associations between EE and obesity, and between attachment security and obesity [68-70], our findings also suggest that attachment security may contribute to healthier weights through healthier eating. Consequently, helping parents to improve their quality of parenting and the attachment security of their infants, may be an effective intervention to prevent $\mathrm{EE}$ and support healthier lifetime trajectories.

Author Contributions: T.v.S. conceived of the presented idea and performed the statistical analyses. R.B. and T.v.S. took the lead in writing the manuscript, with support from M.M., Y.v.d.B. and H.K., Y.v.d.B. has written important parts of the methods. All authors have read and agreed to the published version of the manuscript.

Funding: This research was supported by a Netherlands Organization for Scientific Research VENI grant (016.195.197-to Beijers). Funding for Hanna Konttinen was provided by the Academy of Finland (grants 314135 and 309157).

Institutional Review Board Statement: The study was conducted according to the guidelines of the Declaration of Helsinki, and approved by the Institutional Review Board of the Radboud University (ECG-20213-1811-157).

Informed Consent Statement: Informed consent was obtained from all mothers involved in the study, and from the children when they were 16 years old.

Data Availability Statement: Data available on request from the authors.

Acknowledgments: We thank the families who kindly participated in the NLS study. In addition, we would like to thank CIBERObn, an initiative of ISCIII (ISC III CB06 03/0052).

Conflicts of Interest: Tatjana van Strien has a copyright and royalty interest in the Dutch Eating behavior Questionnaire and manual.

\section{References}

1. Gold, P.W.; Chrousos, G.P. Organization of the stress system and its dysregulation in melancholic and atypical depression: High vs low CRH/NE states. Mol. Psychiatry 2002, 7, 254-275. [CrossRef]

2. Oliver, G.; Wardle, J.; Gibson, E.L. Stress and Food Choice: A Laboratory Study. Psychosom. Med. 2000, 62, 853-865. [CrossRef]

3. Van Strien, T.; Cebolla, A.; Etchemendy, E.; Gutierrez-Maldonado, J.; Ferrer-Garcia, M.; Botella, C.; Baños, R. Emotional eating and food intake after sadness and joy. Appetite 2013, 66, 20-25. [CrossRef]

4. Van Strien, T.; Herman, C.P.; Anschutz, D.J.; Engels, R.C.; De Weerth, C. Moderation of distress-induced eating by emotional eating scores. Appetite 2012, 58, 277-284. [CrossRef] [PubMed]

5. Fong, M.; Li, A.; Hill, A.J.; Cunich, M.; Skilton, M.R.; Madigan, C.D.; Caterson, I.D. Mood and appetite: Their relationship with discretionary and total daily energy intake. Physiol. Behav. 2019, 207, 122-131. [CrossRef]

6. Aoun, C.; Nassar, L.; Soumi, S.; El Osta, N.; Papazian, T.; Khabbaz, L.R. The Cognitive, Behavioral, and Emotional Aspects of Eating Habits and Association With Impulsivity, Chronotype, Anxiety, and Depression: A Cross-Sectional Study. Front. Behav. Neurosci. 2019, 13. [CrossRef] [PubMed]

7. Gibson, E.L. The psychobiology of comfort eating: Implications for neuropharmacological interventions. Behav. Pharmacol. 2012, 23, 442-460. [CrossRef]

8. Koenders, P.; Van Strien, T. Emotional eating rather than lifestyle behavior drives weight gain in a prospective study in 1562 employees. J. Occup. Environ. Med. 2011, 53, 1287-1293. [CrossRef] [PubMed]

9. Bruch, H. Eating Disorders: Obesity, Anorexia Nervosa, and the Person within; Basic Books: New York, NY, USA, 1973.

10. Escobar, R.S.; O'Donnell, K.A.; Colalillo, S.; Pawlby, S.; Steiner, M.; Meaney, M.J.; Levitan, R.D.; Silveira, P.P.; MAVAN Study Team. Better quality of mother-child interaction at 4 years of age decreases emotional overeating in IUGR girls. Appetite 2014, 81, 337-342. [CrossRef]

11. Bowlby, J. Attachment and loss: Volume II: Separation, anxiety and anger. In Attachment and Loss: Volume II: Separation, Anxiety and Anger; The Hogarth Press and the Institute of Psycho-Analysis: London, UK, 1973; pp. 1-429.

12. Lee, A.; Hankin, B.L. Insecure Attachment, Dysfunctional Attitudes, and Low Self-Esteem Predicting Prospective Symptoms of Depression and Anxiety During Adolescence. J. Clin. Child Adolesc. Psychol. 2009, 38, 219-231. [CrossRef]

13. Faber, A.; Dubé, L.; Knäuper, B. Attachment and eating: A meta-analytic review of the relevance of attachment for unhealthy and healthy eating behaviors in the general population. Appetite 2018, 123, 410-438. [CrossRef] 
14. Jewell, T.; Collyer, H.C.; Gardner, T.; Tchanturia, K.; Simic, M.; Fonagy, P.; Eisler, I. Attachment and mentalization and their association with child and adolescent eating pathology: A systematic review. Int. J. Eat. Disord. 2016, 49, 354-373. [CrossRef]

15. Wilkinson, L.J.; Rowe, A.C.; Millings, A. Disorganized attachment predicts body mass index via uncontrolled eating. Int. J. Obes. 2020, 44, 438-446. [CrossRef]

16. Pinquart, M.; Feußner, C.; Ahnert, L. Meta-analytic evidence for stability in attachments from infancy to early adulthood. Attach. Hum. Dev. 2013, 15, 189-218. [CrossRef]

17. Kuipers, G.S.; Bekker, M.H. Attachment, Mentalization and Eating Disorders: A review of studies using the Adult Attachment Interview. Curr. Psychiatry Rev. 2012, 8, 326-336. [CrossRef]

18. Tasca, G.A.; Ritchie, K.; Balfour, L. Implications of attachment theory and research for the assessment and treatment of eating disorders. Psychotherapy 2011, 48, 249. [CrossRef] [PubMed]

19. Zachrisson, H.D.; Skårderud, F. Feelings of insecurity: Review of attachment and eating disorders. Eur. Eat. Disord. Rev. Prof. J. Eat. Disord. Assoc. 2010, 18, 97-106. [CrossRef] [PubMed]

20. Douglas, T.D.; Stephens, J.W.; Barry, J.; Lee, M.D.; Wilkinson, L.L. The influence of attachment orientation on weight loss, eating behaviour and other health outcomes among patients undergoing bariatric surgery: A scoping review. Appetite 2020, 147, 104504. [CrossRef] [PubMed]

21. Leung, S.E.; Wnuk, S.; Jackson, T.; Cassin, S.E.; Hawa, R.; Sockalingam, S. Prospective Study of Attachment as a Predictor of Binge Eating, Emotional Eating and Weight Loss Two Years after Bariatric Surgery. Nutrients 2019, 11, 1625. [CrossRef] [PubMed]

22. Taube-Schiff, M.; Van Exan, J.; Tanaka, R.; Wnuk, S.; Hawa, R.; Sockalingam, S. Attachment style and emotional eating in bariatric surgery candidates: The mediating role of difficulties in emotion regulation. Eat. Behav. 2015, 18, 36-40. [CrossRef]

23. Wilkinson, L.L.; Rowe, A.C.; Robinson, E.; Hardman, C.A. Explaining the relationship between attachment anxiety, eating behaviour and BMI. Appetite 2018, 127, 214-222. [CrossRef]

24. Van Strien, T.; Ouwens, M.A. Effects of distress, alexithymia and impulsivity on eating. Eat. Behav. 2007, 8, 251-257. [CrossRef]

25. Ainsworth, M.D.S.; Blehar, M.; Waters, E.; Wall, S. Patterns of Attachment; Wiley: New York, NY, USA, 1978.

26. Waters, E. Appendix A: The attachment Q-set (version 3.0). Monogr. Soc. Res. Child Dev. 1995, 60, 234-246. [CrossRef]

27. Waters, E.; Deane, K.E. Defining and assessing individual differences in attachment relationships: Q-methodology and the organization of behavior in infancy and early childhood. Monogr. Soc. Res. Child Dev. 1985, 50, 41-65. [CrossRef]

28. Lewis, M.; Feiring, C.; McGuffog, C.; Jaskir, J. Predicting Psychopathology in Six-Year-Olds from Early Social Relations. Child Dev. 1984, 55, 123-136. [CrossRef]

29. Van Bakel, H.J.A.; Riksen-Walraven, J.M. Stress reactivity in 15-month-old infants: Links with infant temperament, cognitive competence, and attachment security. Dev. Psychobiol. J. Int. Soc. Dev. Psychobiol. 2004, 44, 157-167. [CrossRef]

30. Van Ijzendoorn, M.H.; Vereijken, C.M.; Bakermans-Kranenburg, M.J.; Marianne Riksen-Walraven, J. Assessing attachment security with the attachment Q sort: Meta-analytic evidence for the validity of the observer AQS. Child Dev. 2004, 75, 1188-1213. [CrossRef] [PubMed]

31. Cortés-García, L.; Takkouche, B.; Seoane, G.; Senra, C. Mediators linking insecure attachment to eating symptoms: A systematic review and meta-analysis. PLoS ONE 2019, 14, e0213099. [CrossRef]

32. Favieri, F.; Marini, A.; Casagrande, M. Emotional Regulation and Overeating Behaviors in Children and Adolescents: A Systematic Review. Behav. Sci. 2021, 11, 11. [CrossRef]

33. Shakory, S.; Van Exan, J.; Mills, J.S.; Sockalingam, S.; Keating, L.; Taube-Schiff, M. Binge eating in bariatric surgery candidates: The role of insecure attachment and emotion regulation. Appetite 2015, 91, 69-75. [CrossRef] [PubMed]

34. Beijers, R.; Jansen, J.; Riksen-Walraven, M.; De Weerth, C. Attachment and Infant Night Waking: A Longitudinal Study From Birth Through the First Year of Life. J. Dev. Behav. Pediatr. 2011, 32, 635-643. [CrossRef] [PubMed]

35. Beijers, R.; Riksen-Walraven, M.; Sebesta, K.; De Weerth, C. Differential associations between behavioral and cortisol responses to a stressor in securely versus insecurely attached infants. Behav. Brain Res. 2017, 325, 147-155. [CrossRef] [PubMed]

36. Schore, A.N. Effects of a secure attachment relationship on right brain development, affect regulation, and infant mental health. Infant Ment. Health J. Off. Publ. World Assoc. Infant Ment. Health 2001, 22, 7-66. [CrossRef]

37. Belsky, J. Developmental origins of attachment styles. Attach. Hum. Dev. 2002, 4, 166-170. [CrossRef] [PubMed]

38. Cassidy, J. Emotion regulation: Influences of attachment relationships. Monogr. Soc. Res. Child Dev. 1994, 59, 228-249. [CrossRef] [PubMed]

39. Cooke, J.E.; Kochendorfer, L.B.; Stuart-Parrigon, K.L.; Koehn, A.J.; Kerns, K.A. Parent-child attachment and children's experience and regulation of emotion: A meta-analytic review. Emotion 2019, 19, 1103. [CrossRef]

40. Van Strien, T.; Beijers, R.; Smeekens, S.; Winkens, L.H.; Konttinen, H. Parenting quality in infancy and emotional eating in adolescence: Mediation through emotion suppression and alexithymia. Appetite 2019, 141, 104339. [CrossRef]

41. Jaffe, M.; Gullone, E.; Hughes, E.K. The roles of temperamental dispositions and perceived parenting behaviours in the use of two emotion regulation strategies in late childhood. J. Appl. Dev. Psychol. 2010, 31, 47-59. [CrossRef]

42. Waters, S.F.; Virmani, E.A.; Thompson, R.A.; Meyer, S.; Raikes, H.A.; Jochem, R. Emotion Regulation and Attachment: Unpacking Two Constructs and Their Association. J. Psychopathol. Behav. Assess. 2010, 32, 37-47. [CrossRef]

43. Laloyaux, J.; Fantini, C.; Lemaire, M.; Luminet, O.; Larøi, F. Evidence of Contrasting Patterns for Suppression and Reappraisal Emotion Regulation Strategies in Alexithymia. J. Nerv. Ment. Dis. 2015, 203, 709-717. [CrossRef] 
44. Swart, M.; Kortekaas, R.; Aleman, A. Dealing with Feelings: Characterization of Trait Alexithymia on Emotion Regulation Strategies and Cognitive-Emotional Processing. PLoS ONE 2009, 4, e5751. [CrossRef]

45. Larsen, J.K.; van Strien, T.; Eisinga, R.; Engels, R.C. Gender differences in the association between alexithymia and emotional eating in obese individuals. J. Psychosom. Res. 2006, 60, 237-243. [CrossRef]

46. Smeekens, S.; Riksen-Walraven, J.M.; Van Bakel, H.J. The predictive value of different infant attachment measures for socioemotional development at age 5 years. Infant Ment. Health J. Off. Publ. World Assoc. Infant Ment. Health 2009, 30, 366-383. [CrossRef] [PubMed]

47. De Wolff, M.S.; Van Ijzendoorn, M.H. Sensitivity and Attachment: A Meta-Analysis on Parental Antecedents of Infant Attachment. Child Dev. 1997, 68, 571-591. [CrossRef] [PubMed]

48. Van Bakel, H.J.A.; Riksen-Walraven, J.M. Parenting and Development of One-Year-Olds: Links with Parental, Contextual, and Child Characteristics. Child Dev. 2002, 73, 256-273. [CrossRef]

49. Van Bakel, H.J.; Riksen-Walraven, J.M. Quality of infant-parent attachment as reflected in infant interactive behaviour during instructional tasks. J. Child Psychol. Psychiatry 2002, 43, 387-394. [CrossRef] [PubMed]

50. Gross, J.J.; John, O.P. Individual differences in two emotion regulation processes: Implications for affect, relationships, and well-being. J. Pers. Soc. Psychol. 2003, 85, 348-362. [CrossRef] [PubMed]

51. Bagby, R.M.; Parker, J.D.; Taylor, G.J. The twenty-item Toronto Alexithymia Scale-I. Item selection and cross-validation of the factor tructure. J. Psychosom. Res. 1994, 38, 23-32. [CrossRef]

52. Kooiman, C.; Spinhoven, P.; Trijsburg, R. The assessment of alexithymia: A critical review of the literature and a psychometric study of the Toronto Alexithymia Scale-20. J. Psychosom. Res. 2002, 53, 1083-1090. [CrossRef]

53. Rieffe, C.; Oosterveld, P.; Terwogt, M.M. An alexithymia questionnaire for children: Factorial and concurrent validation results. Pers. Individ. Differ. 2006, 40, 123-133. [CrossRef]

54. Van Strien, T.; Oosterveld, P. The children's DEBQ for assessment of restrained, emotional, and external eating in 7- to 12-year-old children. Int. J. Eat. Disord. 2008, 41, 72-81. [CrossRef] [PubMed]

55. Van Strien, T.; Donker, M.H.; Ouwens, M.A. Is desire to eat in response to positive emotions an 'obese' eating style: Is Kummerspeck for some people a misnomer? Appetite 2016, 100, 225-235. [CrossRef] [PubMed]

56. Hayes, A.F. The PROCESS Macro for SPSS and SAS (Version 3.0). 2018. Available online: http://processmacro.org/index.html (accessed on 12 May 2018).

57. Fritz, M.S.; MacKinnon, D.P. Required Sample Size to Detect the Mediated Effect. Psychol. Sci. 2007, 18, 233-239. [CrossRef] [PubMed]

58. Hayes, A.F. Beyond Baron and Kenny: Statistical Mediation Analysis in the New Millennium. Commun. Monogr. 2009, 76, 408-420. [CrossRef]

59. Preacher, K.J.; Hayes, A.F. Asymptotic and resampling strategies for assessing and comparing indirect effects in multiple mediator models. Behav. Res. Methods 2008, 40, 879-891. [CrossRef] [PubMed]

60. Westfall, J.; Kenny, D.A.; Judd, C.M. Statistical power and optimal design in experiments in which samples of participants respond to samples of stimuli. J. Exp. Psychol. Gen. 2014, 143, 2020. [CrossRef]

61. MacKinnon, D.P.; Fairchild, A.J. Current Directions in Mediation Analysis. Curr. Dir. Psychol. Sci. 2009, 18, 16-20. [CrossRef]

62. Blissett, J.; Haycraft, E.; Farrow, C. Inducing preschool children's emotional eating: Relations with parental feeding practices. Am. J. Clin. Nutr. 2010, 92, 359-365. [CrossRef]

63. Braden, A.; Rhee, K.; Peterson, C.B.; Rydell, S.A.; Zucker, N.; Boutelle, K. Associations between child emotional eating and general parenting style, feeding practices, and parent psychopathology. Appetite 2014, 80, 35-40. [CrossRef]

64. Rodgers, R.F.; Paxton, S.J.; Massey, R.; Campbell, K.J.; Wertheim, E.H.; Skouteris, H.; Gibbons, K. Maternal feeding practices predict weight gain and obesogenic eating behaviors in young children: A prospective study. Int. J. Behav. Nutr. Phys. Act. 2013, 10, 24. [CrossRef]

65. Savage, J.S.; Hohman, E.E.; Marini, M.E.; Shelly, A.; Paul, I.M.; Birch, L.L. INSIGHT responsive parenting intervention and infant feeding practices: Randomized clinical trial. Int. J. Behav. Nutr. Phys. Act. 2018, 15, 64. [CrossRef] [PubMed]

66. Wei, M.; Vogel, D.L.; Ku, T.-Y.; Zakalik, R.A. Adult Attachment, Affect Regulation, Negative Mood, and Interpersonal Problems: The Mediating Roles of Emotional Reactivity and Emotional Cutoff. J. Couns. Psychol. 2005, 52, 14. [CrossRef]

67. Brenning, K.M.; Soenens, B.; Braet, C.; Bosmans, G. Attachment and depressive symptoms in middle childhood and early adolescence: Testing the validity of the emotion regulation model of attachment. Pers. Relatsh. 2011, 19, 445-464. [CrossRef]

68. Diener, M.J.; Geenen, R.; Koelen, J.A.; Aarts, F.; Gerdes, V.E.A.; Brandjes, D.P.M.; Hinnen, C. The significance of attachment quality for obesity: A meta-analytic review. Can. J. Behav. Sci. Rev. Can. Des Sci. Du Comport. 2016, 48, 255. [CrossRef]

69. Lee, H.A.; Lee, W.K.; Kong, K.-A.; Chang, N.; Ha, E.-H.; Hong, Y.S.; Park, H. The Effect of Eating Behavior on Being Overweight or Obese During Preadolescence. J. Prev. Med. Public Health 2011, 44, 226. [CrossRef] [PubMed]

70. Swinburn, B.A.; Sacks, G.; Hall, K.D.; McPherson, K.; Finegood, D.T.; Moodie, M.L.; Gortmaker, S.L. The global obesity pandemic: Shaped by global drivers and local environments. Lancet 2011, 378, 804-814. [CrossRef] 